\title{
GPPS-CH-2020-\#169
}

\section{GRID BALANCING IN FUTURE ENERGY LANDSCAPE - A MATTER OF COST OPTIMIZATION.}

\author{
B.Anders Stuxberg \\ Siemens Energy $A B$ \\ anders.stuxberg@siemens.com \\ Finspang, Sweden
}

\begin{abstract}
This paper presents challenges and solutions to how a typical future energy system might be structured, roles of different equipment and plants and how they would be expected to interact to achieve cost efficient power balancing of an electric grid mainly supplied by renewable wind and solar. Energy storage and demand response will play significant roles and so will gas turbines in simple and combined cycle. Hydrogen and power to $\mathrm{X}$ is envisaged as the ultimate solution for balancing power to become fossil-free but there will be other fuels too, e.g. biogas, bio-methanol, ethanol, renewable diesel. Which systems and fuels to use will most probably be a matter of availability and cost, which to a large extent will be a matter of minimizing capex for components used for limited operating hours whilst fuel cost and efficiency will be decisive for systems operated many hours. Gas turbine plants may fill more than one function in grid balancing, which means good usage of capital. Highly flexible CHP (Combined Heat and Power) plants can play a key role in grid balancing should that be appreciated by regulators. The use of heat pumps instead of CHP, or in parallel to flexible CHP, is also expected to become common practice.
\end{abstract}

\section{BACKGROUND}

With the increased share of renewable power, the residual load (defined as total demand minus renewable power at any instant) decreases. Variations in the residual load increases due to overlaid demand variations with supply variations, i.e. the relative control variations in residual load increase significantly, both in shorter and longer time frames. At the same time the inertia in the grid is carved out and errors in forecasts tend to increase. All combined, results in new flexibility demands for the residual load.

The following article is based on the assumption that; political powers succeed in stopping the use of fossil fuels in the power sector, then it is a given that the use of renewable power must increase significantly, storage solutions must be used and the remaining sector of residual load providers only operate on renewable fuels. Renewable fuels will be more costly and the price for fossil fuels will become very low due to the decrease in demand. Legislation and carbon dioxide taxes will come into force in order to block the use of fossil fuels.

When this will take place is unclear, but given the current global situation, it may come faster than we imagine. The purpose of this article is to give a high-level picture only; future winners will be different for different conditions and markets. The mixture of solutions will result from price development, greatly driven by market forces different in comparison to today's traditional conditions.

\section{TOOLS FOR GRID BALANCING IN A FUTURE DE-CARBONIZED ENERGY SYSTEM}

Balancing the grid with coal fired power plants, operated mostly at inefficient part load to be ready to take load, should be a soon ended strategy. Natural gas fired combined cycle power plants are an intermediate step towards a sustainable future since the carbon dioxide release per $\mathrm{kWh}$ at full load is reduced to less than $50 \%$ and the plants can operate more flexibly, thus avoiding inefficient idling. But if that solution is only an intermediate step, will then investment in such a plant mean that a lock-in effect is created and that owners may be left with stranded assets when new solutions are required? 
My answer is no, given that the plant design takes the future requirements into consideration. Some building blocks in terms of future fuels and choice of technology are discussed in the following.

\section{Energy Storage}

Energy storage has been proposed to solve the issue of intermittent supply of renewable power, but all types of storage are limited in continuance, it will not be economical to size capacity to cover all events. Examples of energy storage systems and ranges of suitable power and continuance are tabled below:

\begin{tabular}{|l|l|l|}
\hline Storage type & Capacity & Continuance \\
\hline Super capacitor & $<1 \mathrm{MW}$ & milliseconds \\
\hline Flywheels & $1-100 \mathrm{MW}$ & Milliseconds - seconds \\
\hline Batteries & $<100 \mathrm{MW}$ & Milliseconds - 8 hours \\
\hline Thermal storage & $1-300 \mathrm{MW}$ & Hour - days \\
\hline Pumped hydro & $100-5000 \mathrm{MW}$ & Minutes - days (weeks) \\
\hline Gravity storage & $<10 \mathrm{MW}(100 \mathrm{MW})$ & Minutes - hour (days) \\
\hline Compressed / liquid air storage & $10-1000 \mathrm{MW}$ & Hours - week \\
\hline
\end{tabular}

Table 1 Examples of Energy Storage Systems

Pumped hydro is normally optimized for one day, possibly up to a week storage, unfortunately a topology with large height differences and access to water is required, thus possible global capacity is rather limited. Investment is very high, but cycle cost is low and round-trip efficiency is good.

Battery storage systems are not suitable for long duration even if they are economical for short cycles.

A $1000 \mathrm{MW}$ battery storage for 2-week duration packed in containers would require a $3000 \mathrm{~km}$ row of containers! (assumes lead cells that are most economic for such duty). Round trip efficiency is high, typically above $80 \%$. However, most battery systems suffer from high cycle cost due to limited cycle life of batteries, future cost expected to drop to about 5 cents 2025 and 3cents 2040 per kWh discharged. Cycle cost here simply calculated by dividing battery replacement cost over cycle life 3500 cycles @ 80\% dept of discharge (Mongird et al. 2019), battery module cost 150 USD/kWh 2025 and 75 USD/kWh 2040 (Huntington and Jansen 2020) plus own estimate of 25 USD/kWh for replacement work.ravity storage systems provide far too little capacity to become a cost-efficient alternative for large energy contents, unless you lift a hole mountain hydraulically. $100 \mathrm{MW}$ capacity for 12-hour duration requires about 5 million tons of weight if lifted $100 \mathrm{~m}$.

Thermal storage is either of high temperature type for power production or low temperature for heat provision. In the first case it may be based on molten salt, as already applied in combination with thermal solar plants of today, or other storage media like concrete, in both examples using steam turbine technology for discharge. Round trip efficiency is low, about $30 \%$ but cycle cost is very low. The constant heat loss from the storage limits the time to store energy, at very large scale the heat loss issue is reduced.

Compressed air energy storage (CAES) saves compressed air in a very large pressure vessel, preferably an underground cavern, to later expand the air again to provide power. To improve power capacity and efficiency it may be combined with a heat storage saving heat from compression, plus potentially more direct heat input by combustion during discharge. Round trip efficiency is about 50\% (Mongird et al. 2019), i.e. better than thermal storage, and cycle cost is low. Main drawback is the need for suitable underground caverns, e.g. salt domes or depleted natural gas pockets. Liquid air Energy Storage is a version where air is stored in liquid form, created by a cryogenic process. It does not depend on large caverns but requires ultra-insulated cryogenic storage instead with a related issue with limited storage time due to "boil-off", i.e. heat dissipation into the storage.

Cost that has been proposed for future large-scale storage systems per installed storage capacity is 165 USD/kWh for pumped hydro, $105 \mathrm{USD} / \mathrm{kWh}$ for CAES (Mongird et al. 2019) and $156 \mathrm{USD} / \mathrm{kWh}$ for battery storage year 2050 (Cole and Frazier 2019).

Electric production cost through arbitrage from energy storage may be estimated according to the following calculation example: Assume cost of purchased electricity 50 Euro/MWh, $80 \%$ roundtrip efficiency, a straight payoff of capital of e.g. $150 \mathrm{Euro} / \mathrm{kWh}$ over 10 years and that one cycle per week is exercised, then the electric price from the storage must be $50 / 0.8+150 * 1000 / 10 / 52=351$ Euro/MWh or higher. By this simple calculation it becomes evident that the Capex part is completely dominating when operating few cycles per year. If we now assume one cycle per day, then the Capex part comes down to 41 Euro/MWh and the total to 104 Euro/MWh. If you add a cycle cost in case batteries are studied for daily cycles, then the cost is about 150 Euro/MWh.

One cannot assume that substantial amounts of renewable power can be purchased at zero or even negative cost for charge of a storage, the occurrence of such pricing today is only the effect of subsidies systems that are soon history. 
Storages systems of today typically find their revenue from ancillary services (capacity market, fast frequency response, reactive power compensation etc.) and not the energy arbitrage as outlined in the example above.

\section{Demand response / virtual power plants}

In most societies there are power demands that can be controlled to assist in the frequency control of the grid. Volatile pricing will release a lot of capacity by plain market forces. Some large industrial electricity consumers offer their service to the grid operators already today, and small scaled demands like air conditioning or heating can be run on/off or at varied power without affecting the user very much. Long term an intentional increase of thermal capacity and improved insulation of buildings will enable a more dynamic operation of climate conditioning systems. With new IT-solutions, many small demands can be clustered and controlled to balance the grid across time constants up to a few hours. Batteries in electric vehicles can also be used for balancing within the day-scale.

New demands that are designed to adapt to grid price variations will also come to play, e.g. large electric driven heat pumps with heat storage for district heat supply.

\section{Conventional boiler with steam turbine}

A conventional boiler with steam turbine is inflexible and not suitable for frequent start and stops to balance residual power demand, cycling in the scale of intra-day or even for a few days. If designed for renewable fuel, the electric efficiency is also rather low. They may be cycled in load and kept at lower, inefficient power to avoid stop and restart. A boiler plant for residual load operation would get a poor plant utilization since short or medium length peaks cannot motivate starts. If you then consider that boiler plants are very expensive to construct, you can see that high capital cost combined with poor utilization makes it an uneconomical investment. An existing, already written off boiler could of course be converted to biomass but the cost for such conversion may be high and only worthwhile if the plant is relatively new and designed with suitable steam conditions. One clear benefit of a boiler is that simple forms of biomass can be used, e.g. wood chips which suggests a low fuel cost. However, this relies on a continued low-cost supply of the biomass. An addition of a high temperature thermal energy storage, as discussed above, can improve the ability for a boiler plant to operate more flexible, using the storage for daily cycles and the boiler for long continuance. Charging of storage is then assumed to be made by import of cheap electricity and not by firing the boiler.

\section{Solar thermal plant}

A solar thermal plant collects solar heat radiation by either through type of collectors heating a thermal oil, or by a matrix of mirrors concentrating the radiation to a boiler positioned in a central collector tower. The steam produced by the boiler is used in a steam turbine to produce electric power. In the case thermal oil is used as intermediate media, a boiler uses the hot oil to produce steam. Today the cost of the competing technology; PhotoVoltaic solar panels (PV) has dropped so much that the thermal type of plant is only of interest when combined with a heat storage, typically using molten salt as storage media. This enables continued steam turbine operation during evening and at night and keeps the steam turbine hot and ready for load increase in the morning when solar input returns.

\section{Gas turbine technology}

A gas turbine plant can be designed and built specifically for flex operations and be very efficient allowing daily starts, with fast start capability to keep start cost down. Such flex-plant can also handle large load gradients and provide a large inertia to the grid.

Gas turbines are very low in specific cost which is of key importance when discussing back-up and reserve power, i.e. the last balancing resources that get little dispatch. In such installations simple cycle configuration is the most economical. Traditional peaker plants may be pushed into the regime as back-up if demand-response and storage solutions take over much of the intra-day variations. Traditional base load plants may also be pushed back in dispatch to operate as balancing resources ranging from a scale of one day to many weeks. Even if the dispatch becomes low, the efficiency should preferably be high to minimize consumption of the renewable fuels that will be more costly than today's fossil fuels.

If a plant is specified for best performance, it may not be future proof as it may be too inflexible. To make a combined cycle plant flexible and fast starting, the steam cycle design may be based on fairly simple steam parameters and some measures be taken to preserve heat in the HRSG (Heat Recovery Steam Generator) during standstill. A gas turbine in itself may be fast starting, e.g. SGT-800 is available for 10-minute start, cold to full load. With the appropriate design an HRSG can accept fast GT start also from cold condition, the HRSG pressure parts are ramped in pressure/temperature independently from the exhaust and are thus not very exposed to stress despite fast GT start. The full gas turbine power can thus be provided at short notice and the steam cycle power contribution comes with a certain time lag.

By using low steam pressure in the steam cycle, faster ramps for pressure build during start can be accepted and the goal pressure is also less, $i^{.} e^{1 / 2}$ pressure $=1 / 4$ start time. If a lower steam temperature is selected, less sensitive material may 
be used, and the ramp can be increased even further, the result may be a steam cycle- start to full load in- $<40$ minutes instead of 4 hours.

A gas turbine that also can utilize different fuels flexibly may be operated shifting between different fuels differently suited to the operating time frame, cost or fuel availability, see below for more information.

It may seem a paradox that gas turbine design should be highly efficient and the steam cycle not. Gas turbine efficiency combined with high or fair exhaust temperature is key for plant efficiency but does not hinder fast start capability. The high efficiency of a gas turbine also results in high specific power for the machine, which in most cases gives less specific cost. For the steam cycle less advanced steam parameters reduces cost. As in the case of a boiler plant also a high temperature energy storage can be added to the steam bottoming cycle to further improve flexibility, increase steam cycle utilization and make a share of used energy input renewable electric power rather than fuel.

\section{Fuel cells}

Fuel cells may be well suited for small scaled applications like vehicles, microgrid or small grid applications. However, they are tailored for one fuel only, have a too limited life-length and suffer from insufficient economy of scale to suit powerplants at many MW scale. For the small scaled applications, they provide high efficiency, up to $60 \%$ when operated with hydrogen fuel, and potentially easy plug-and play unmanned operation, which is key for plant economics. Reliability is also very high since no moving parts are involved and operating temperature is low. Investment cost for Proton Exchange Membrane (PEM) type is projected at 1727 USD/kW @ $250 \mathrm{~kW}$ capacity and > 10000 systems supply (Batelle 2016), large scaled vehicle implementation may though bring cost to lower levels.

After a fuel cell is started and has reached normal working temperature it is typically very fast in ramping load, a PEM type should be able to ramp major part of its load capability in less than a second, depending on capability of fuel and air supply systems. The PEM type should be the preferred choice for a backup/balancing system as it is better suited to start/stop than other types.

\section{Reciprocating engines}

Reciprocating engines compete with gas turbines and one could write a whole article only around pros and cons. Keeping it short though; recips come in a number of categories, high speed, fast starting machines are good as emergency back-up power whilst low speed gas engines are better for power gen. applications, such machines may start in 5-minutes if machines are kept warm, else some 20 minutes. They are more limited in capacity than GT:s, i.e. many machines must be installed to build up a power gen site, benefit of that is good part load efficiency by staged operation. They have high emissions levels and have less efficiency than combined cycles, which is negative for flex baseload. They provide a much less inertia and primary response per capacity than gas turbines and, in case of gas firing, are much more sensitive to grid disturbances. They are more expensive per capacity than simple cycle GTs (with the exception for emergency diesels gen sets that have short life length). The maintenance cost is also high and frequent oil replacement is required.

\section{CHP, Combined Heat and Power}

CHP plants can, if made flexible, offer a large capacity for grid balancing. If you need to provide the heat anyway, then the added fuel consumption to also provide electricity is small: Typically, you may find a marginal efficiency from added fuel to gained electric output at about $85 \%$. Simple homework for the interested reader; prove this figure by calculating electric production and fuel usage at a given heat supply for two cases, e.g. $30 \%$ and $50 \%$ electric efficient plants having the same total efficiency, e.g. $87 \%$.

If the operation can be adapted to provide the electricity when needed most, then this becomes very efficient. By adding large heat storages to the hot water side of district heat production, a CHP plant can be dis-coupled from the heat demand and even operate on/off, it only needs to match its heat output as an average to the heat demand. If we also consider that fuel consumption for heating purposes in Europe are on par with fuel consumption for electric power production, then it's obvious that CHP has the potential to become a powerful grid balancing resource.

A modern CHP plant, based on a flexible modern gas turbine, with a steam bottoming cycle based on backpressure and a large heat storage at the district heat supply, can operate very flexibly and on/off operation is fully possible. At a given heat demand, the high electric efficiency compared to a conventional steam boiler set-up results in that the electric production is about doubled. Fuel utilization of such a plant is in the range of $87-89 \%$. Note that even when operated on natural gas, the $\mathrm{CO}_{2}$ released is well below $250 \mathrm{~g} / \mathrm{kWh}$ as required for loans under the EIB (European Investment Bank) new lending policy (new EIB requirements is just one of many indicators of the change to a more sustainable era).

An interesting phenomenon is that by on/off operation, the required plant size is increased to provide a given average heat output. If e.g. dispatch of electricity is requested $25 \%$ of the time, then the CHP plant should be 4 times bigger than a CHP plant that operates continuous without heat storage. This means that economy of scale of the CHP plant is improved and the capacity for grid balancing by CHP becomes much greater than anticipated today. It is also worth considering that CHP plants are often located where the electric demand is found, i.e. distributed power generation with all the benefits of reduced transmission losses etc. that follows. 
Note that conventional condensing/extraction solution is not suitable as the condensing mode would rarely be required and the last steam turbine stages requires a constant cooling flow $=$ loss of heat to ambient. A backpressure solution is more suitable and can be equipped with a heat exchanger to enable dumping of heat to ambient if the heat storage is full and electric demand is high, allowing full plant load to be operated similarly to a condensing/extraction solution.

If large scaled heat pumps are installed parallel to the CHP plant, the need for heat storage is reduced and the capacity of the CHP should not be increased as much as with no heat pump installed.

\section{Industrial CHP}

Power plants that deliver process steam for industrial use cannot use heat accumulators for on/off operation as easily as in the case of district heat supply. However, they can operate somewhat flexible by dumping low grade heat to ambient when the electric price is high and steam demand is less than full rating. A backpressure solution will most probably be more economic than condensing/extraction and will emit less than $250 \mathrm{gr} \mathrm{CO} / \mathrm{kWh}$ as required for EIB loans.

To enable full load at low steam demand, a dump condenser that takes process steam to heat ambient air can be added, or alternatively a condensing tail (LP steam turbine with self-synchronizing clutch) that is only activated in such situations. High temperature thermal energy storage can be added to increase load flexibility also for these plants or even enable on/off operation. Cheaper heat accumulators using hot pressurized water, can also be applied for low pressure steam systems.

\section{FUTURE FUELS}

Future fuels for use in balancing power plants should in the long term be renewable even if the number of operating hours is small, a high fuel cost will not matter so much when the consumption is limited. The power sector is more focused on decarbonization in comparison to for example steel manufacturing or civil construction and this may lead to requirements for renewable operation long before a similar change is required in other businesses. This is a bit unfortunate if the result is low degree of sector intercoupling and later creates competition for renewable resources like biomass. An increase of wood usage in the construction business may lead to more wood residues to be used by the power or petrochemical sectors. But then the forestry business should be guided to timber production and not to plantation of energy crops.

A far from comprehensive summary of considerable fuels follows below.

\section{Hydrogen}

Hydrogen may be produced by steam reforming of natural gas (called blue hydrogen) where carbon dioxide is returned to underground storage in liquid form. Such process requires the transport of hydrogen to users or transport of natural gas plus return transport of carbon dioxide. Transport of hydrogen in substantial amounts requires conversion to liquid form, i.e. cooling to $-253^{\circ} \mathrm{C}$, which is rather costly and takes a toll in power demand. Steam reforming from natural gas where $\mathrm{CO}_{2}$ is released to ambient is called grey hydrogen.

Hydrogen may also be produced by hydrolysis, the separation of water by electricity. If renewable electricity from e.g. wind and solar is used, the hydrogen from hydrolysis may be called green. Efficiency of hydrolysis to hydrogen lower heating value is in the range $60-75 \%$, after compression some $5 \%$ less. Hydrogen production by hydrolysis may be performed at the site of usage. The hydrolyser equipment requires a sizeable investment and could lead to a low Return on Investment if the utilization is low. Thus, the best gas cost is found if one assumes dedicated renewable power with high utilization factor that feeds only the hydrolysers even though you have to pay for the power. If we simplify and assume that cost of power is 40 Euro per MWh, that the cost of the hydrolysers, water treatment and short term hydrogen storage adds another 40 Euro per MWh electric infeed by assuming that investment is in par with that of the power generation and same utilization factor applies, and that we have $70 \%$ electric to hydrogen efficiency, then the cost of hydrogen is 114 Euro per MWh.

Hydrogen requires large volumes at very high pressure to be stored in gaseous form. Gas volume required for operation of one $50 \mathrm{MW}$ gas turbine for one week is about the same as the volume of two salt-mines. Purpose made gas-domes in salt-findings may be made somewhat larger. Storage in gas tanks is managed by building tanks consisting of bottles/pipes at diameter less than one meter to avoid too extreme wall thicknesses. Such storage would have little scale benefit as a large storage just requires many more bottles or very long pipes. Up to few days of storage is expected as maximum economical limit when considering also cost reductions by learning and series production.

Liquefaction of hydrogen at site of the power plant is possible but adds cost and consumes power. A cryogenic process should preferably be rather large scale to become cost efficient, i.e. co-location with a power plant would be cost efficient only at large power plants. As with handling of LNG any heat transfer in the storage results in boil-off of hydrogen, which is a loss if not released hydrogen gas is utilized in an efficient way.

Transport of hydrogen is difficult, at large scale liquid form of hydrogen is necessary or pipelines should be applied. Use of existing natural gas pipeline grid is discussed but seems limited to a blend-in into natural gas at up to $15 \%$ by volume (about $7 \%$ of energy). Any new machine installed should be able to handle at least this amount. 


\section{Power to X}

Power to X covers the production of many types of chemical substances or fuels by energy input from electricity. For this paper, two options are covered: methanol and ammonia. Both substances can be used as gas turbine fuel and are handled in liquid form. They can be stored for prolonged periods without any loss and storage can also be large scale if needed for continuous power plant operation. An aspect is that power production far away from users can be utilized for fuel production, e.g. at offshore wind parks.

\section{e-Methanol}

Methanol is produced by first producing hydrogen and then combine with carbon dioxide in a reactor. If carbon dioxide put into the reactor is captured from ambient air then it's easy to see that the carbon dioxide is in a loop, not adding to greenhouse gases. The same applies if carbon dioxide is captured from a power plant or other process where otherwise it would been released to atmosphere.

Even if methanol is poisonous for humans it's not for the ambient, i.e. small spills in nature are not harmful. It is not explosive, and it has very good combustion properties. The boiling point at atmospheric pressure is $64.7^{\circ} \mathrm{C}$, i.e. it stays in liquid form with no chilling required or boil off occurring. One could easily transport methanol in society the same way we today handle e.g. diesel oil and there is no aging or decomposition taking place if stored for long periods, as is the case can be with diesel. The cost of conversion to methanol from hydrogen is low, however, the cost of recovery of carbon dioxide needed for the process may be high. On the assumption that conversion to methanol adds $50 \%$ to the cost of hydrogen, using the hydrogen cost above, the cost is set to 170 Euro/MWh.

\section{Ammonia}

Ammonia is also produced by first producing hydrogen and then combine with nitrogen that can be captured from air. During combustion of ammonia no carbon is present so no greenhouse gas results if $\mathrm{NO}_{\mathrm{x}}$ formation can be avoided. Modern combustion technology combined with a de- $\mathrm{NO}_{\mathrm{x}}$ catalyst downstream combustion should manage this.

The boiling point of ammonia is $-33.34^{\circ} \mathrm{C}$ at atmospheric pressure. Thus, either a pressurized storage is needed or some boil-off from an atmospheric storage must be accepted. Boil-off gas can in this case with reasonable effort be compressed, cooled and depressurized to be returned as liquid to the storage.

In case of leakage, ammonia is a lethal gas, thus transport and storage require many safety precautions. However, ammonia is handled in large quantities already today as it is one of the most common base chemicals and used as fertilizer. In low concentrations ammonia is non-poisonous as it is part of many biological processes.

Continuing with cost estimates for ammonia production in a power to X scheme, let's assume that cost increase from hydrogen cost is $+30 \%$, i.e. 150 Euro/MWh using the same hydrogen cost as assumed above.

\section{Bio-fuels}

Bio-fuel options for future use in gas turbines that I like to bring up for discussion are biogas, bio-methanol, ethanol and renewable diesel.

\section{Biogas}

Biogas is produced by fermentation of organic waste, manure and sewage sludge. Gas quality is typically $65 \%$ or more methane and the rest mainly carbon dioxide. This gas quality may possibly be used as is directly in gas turbines (not all GTs are able yet). The gas can also be upgraded to meet natural gas specifications to be allowed to be injected into natural gas grids or to be sold as fuel gas for cars. When upgraded, it can also be liquified and is then sold under tradename LBG (liquid biogas). When stored in compressed storage it is less bulky than hydrogen, energy density is $2-3.5$ times that of hydrogen. When stored in liquid form it's the same as LNG, i.e. cryogenic at $-162 \mathrm{C}$ with related costs and boil-off issues.

The cost of biogas is hard to estimate as it is mainly a byproduct from waste management which should bear the main part of the cost. The price of biogas is commonly set by market forces to match competition by other fossil vehicle fuels. Production capacity is commonly rather limited by access of feedstock and to offset of remaining composted sludge.

\section{Bio-methanol}

Bio-methanol is produced by thermal gasification of biomass e.g. forestry waste, agricultural waste, bagasse (sugarcane-waste), black liquor from paper mills or recycled waste of biologic origin. The feedstock should be certified as sustainable, as when timber is used for construction of houses and waste such as tops, branches and sawdust is used for methanol production and new trees are planted to maintain a continuous circular system.

Production cost of bio-methanol naturally depends on cost feedstock. If wood waste cost 30 Euro per MWh and the conversion process is assumed to have $80 \%$ efficiency and we assume that the large-scaled cost of the conversion doubles the cost, then methanol cost should be about 80 Euro per MWh. This is about 50\% higher than current price of fossil-based methanol. However, in a future fossil-free scenario, methanol will be an important base chemical and if bio-methanol production capacity becomes less than demand, then the market price will rather be set by power to $\mathrm{X}$ methanol production 
cost. If hydrogen is introduced to the bio-methanol production then $\mathrm{CO}_{2}$-output is avoided and methanol production is enhanced by about $70 \%$, hydrogen should then preferably be green hydrogen. An interesting aspect is the wide usage of methanol, it will surely be available everywhere and there are alternative renewable production routes (bio-methanol, Power to X).

\section{Ethanol}

Ethanol is produced by the fermentation of e.g. sugar from sugarcane, corn or crops.

Ethanol is in liquid phase at atmospheric pressure, boiling point $78.24^{\circ} \mathrm{C}$, and has very nice combustion properties. Ethanol is slightly cheaper to produce than bio-methanol but farming of feedstock to the production competes with food production. The carbon dioxide footprint of ethanol production is not as good as for bio-methanol production, mainly due to use of fertilizers and agricultural energy consumption. If a forest is cut down to create new ground for sugarcane plantation then the single release of carbon dioxide by that de-forestation is also a burden for the ethanol alternative. Ethanol is widely used as fuel in the transport sector. The future price of ethanol may be ruled by the market and not production cost and the transport sector is expected to change to more renewable fuels in addition to the wider usage of electric cars, holding back demand increase for ethanol fueled cars.

\section{Renewable diesel}

Renewable -diesel may be produced by a number of methods from a variety of origins, e.g. tallow or vegetable oil that is reacted with an alcohol or pyrolysis-oil that is treated with hydrogen in a catalytic process.

Generally renewable diesel can fulfill the specifications applicable for fossil low Sulphur diesel for use in a gas turbine. Production cost of renewable diesel is strongly dependent on the cost of feedstock, e.g. in the case of tallow, it stands for $80 \%$ of the product cost. Price level today is around 80 Euro per MWh. Some vegetable fats and vegetable oils are wastes and then have low cost but also limited capacity. Vegetable oils produced solely for the diesel production will compete with food production which is not the case if forest residues are used in a pyrolysis process. Renewable diesel is considered a quick fix to turn the transport sector green since it's a straight drop-in, replacing fossil diesel. As in the case of ethanol one may expect that market forces will rule the pricing rather than the production cost.

\section{Conclusion regarding future renewable fuel prices.}

There are numerus reports about production cost of the different fuel types. One may see some tendencies such as that ethanol from sugarcane should be slightly less costly than bio-methanol and that methanol by power to X should be more expensive than bio-methanol. Will hydrogen self-produced at sites of power plants be cheaper than bio- fuel? As always it will depend on several factors, not at least market forces. Some claim that biofuels will be insufficient for the demand but that of course depends on how big the demand is and what feedstocks are used. Before the capacity limit is hit, the discussion of that limit is rather irrelevant. There will be large differences globally due to varying access to usable wastes and climate conditions. Domestic fuel production will be valued by all countries that have issues with national trade balance. Production costs for many new fuels are also just theoretical exercises, as differences in real large-scale future production costs may be less than differences in methods used in different studies made. The future fuel price a customer will have to pay will be set mainly by market forces and only secondly by actual production cost. Thus, I am reluctant to give any cost references to enforce a credibility as most probably they will be proven wrong and misleading, prediction of future pricing cannot ever be scientific. By this reason production costs discussed for the fuels listed above have been generated by simplified own calculations based on simplified assumptions just to demonstrate some logics that should apply.

My main argument is that you should be prepared for a number of options and avoid a lock-in situation

Siemens gas turbines are already very fuel flexible and the journey to ability for use of new fuels is well underway. 


\section{Conclusion regarding future renewable fuel practical aspects.}

Table 2 below summarizes fuel storage properties and fuel storage volume required for one week operation of one 50 MW, 40\% efficient gas turbine at full load. For compressed hydrogen it assumes a 70 bar underground storage, whilst for biogas a 350 bar storage in composite cylinders. Volumes have been calculated by typical heating values for each fuel, volumes for the liquid options is a less than tanks often seen today. A hydrogen storage of $100000 \mathrm{~m} 3$ would be a underground dome of some 30 meter diameter and 100 meter height. If a 1.1 meter diameter pipeline would be used for a hydrogen storage of this size it would be 100 kilometers long.

\begin{tabular}{|l|l|l|l|l|}
\hline & $\begin{array}{l}\text { Boiling } \\
\text { point }{ }^{\circ} \mathrm{C}\end{array}$ & $\begin{array}{l}\text { Storage } \\
\text { pressure bar }\end{array}$ & $\begin{array}{l}\text { Storage } \\
\text { temperature }{ }^{\circ} \mathrm{C}\end{array}$ & $\begin{array}{l}\text { Storage } \\
\text { volume } \\
\text { m3 }\end{array}$ \\
\hline $\begin{array}{l}\text { Hydrogen } \\
\text { compressed }\end{array}$ & -253 & 70 & $\mathrm{amb}$ & 100000 \\
\hline $\begin{array}{l}\text { Hydrogen } \\
\text { liquid }\end{array}$ & -253 & $\mathrm{amb}$ & -253 & 8900 \\
\hline e-methanol & 64.7 & $\mathrm{amb}$ & $\mathrm{amb}$ & 4800 \\
\hline Ammonia & -33.34 & $\mathrm{amb}$ & -33.34 & 5600 \\
\hline Bio-gas & -162 & 350 & $\mathrm{amb}$ & 5900 \\
\hline $\begin{array}{l}\text { Bio- } \\
\text { methanol }\end{array}$ & 64.7 & $\mathrm{amb}$ & $\mathrm{amb}$ & 4800 \\
\hline Ethanol & 78.24 & $\mathrm{amb}$ & $\mathrm{amb}$ & 3300 \\
\hline $\begin{array}{l}\text { Renewable } \\
\text { diesel HVO }\end{array}$ & $>180$ & $\mathrm{amb}$ & $\mathrm{amb}$ & 2200 \\
\hline
\end{tabular}

Table 2 Storage properties of renewable fuels

Table 3 below summarizes some scores from $1=$ poor to $5=$ good. These scores are just personal simplified opinions where score 1 does not necessarily mean a showstopper. Feedstock availability and competition with other sectors may be non-issues until a limit is reached where it starts to affect pricing only or actually becomes a constraint. HVO diesel stands for Hydrogenated Vegetable Oil, here representing feedstock that competes with food production.

\begin{tabular}{|l|l|l|l|l|l|l|l|}
\hline & $\begin{array}{l}\text { Storage } \\
\text { issues }\end{array}$ & Transportable & Safety & $\begin{array}{l}\text { Combustion } \\
\text { properties }\end{array}$ & $\begin{array}{l}\text { Feedstock } \\
\text { availability }\end{array}$ & $\begin{array}{l}\text { Competes } \\
\text { with food }\end{array}$ & $\begin{array}{l}\text { Competes } \\
\text { with transport } \\
\text { or chemicals }\end{array}$ \\
\hline $\begin{array}{l}\text { Hydrogen } \\
\text { compressed }\end{array}$ & 1 & 1 & 2 & 1 & 5 & 5 & 5 \\
\hline $\begin{array}{l}\text { Hydrogen } \\
\text { liquid }\end{array}$ & 2 & 3 & 2 & 1 & 5 & 5 & 5 \\
\hline e-methanol & 4 & 5 & 5 & 4 & 4 & 5 & 2 \\
\hline Ammonia & 4 & 4 & 2 & 1 & 5 & 5 & 2 \\
\hline Bio-gas & 2 & 2 & 4 & 5 & 1 & 4 & 4 \\
\hline $\begin{array}{l}\text { Bio- } \\
\text { methanol }\end{array}$ & 4 & 5 & 5 & 4 & 4 & 5 & 2 \\
\hline Ethanol & 4 & 5 & 4 & 4 & 2 & 1 & 2 \\
\hline $\begin{array}{l}\text { Renewable } \\
\text { diesel HVO }\end{array}$ & 5 & 5 & 4 & 5 & 2 & 2 & 1 \\
\hline $\begin{array}{l}\text { Renewable } \\
\text { diesel other }\end{array}$ & 5 & 5 & 4 & 5 & 4 & 5 & 1 \\
\hline
\end{tabular}

Table 3 Scores for renewable fuel aspects 


\section{SUITABILITY OF DIFFERENT RESOURCES FOR GRID BALANCING}

As briefly described above, the grid must be balanced in all time frames ranging from seconds to many weeks or even seasons. Different technologies are differently suited to economically provide balancing power in different time frames. E.g. storage solutions (not including Power to X) and demand response are well suited for intra-day response but will be very expensive if sized for longer duration and even if you try to size them to cover all considerable time frames there will anyway be occasions when you need to operate even longer.

Generally, when balancing a mixture of wind and solar power, the probability for events where the residual load provider needs to operate, falls by longer continuance. It's less probable that a plant should be needed for a two-week period than for a one-week period. There are of course seasonal variations too that needs to be compensated. Events of very long continuance for residual load dispatch will thus be rare and create rather little operating hours across the life of a plant. The cost will then be dominated by the CAPEX for plant and for fuel storage, which must be minimized, e.g. by using simple cycle GT with a cheap to store liquid fuel. At the other end of the range of continuance, plants that can capture shorter events of residual load demand will dispatch for more hours and then efficiency and fuel energy cost is more important than the capex.

Picture 1 below, with certain focus to GT plants, shows as a principle the ranges in continuance where different technologies are suitable.

\section{Boiler Plant using fixed bio-fuel}

GT Plant / Flex CHP using liquid bio-fuel or e-fue

GT Plant / Flex CHP using liquified hydrogen

GT Plant / Flex CHP using hydrogen gas

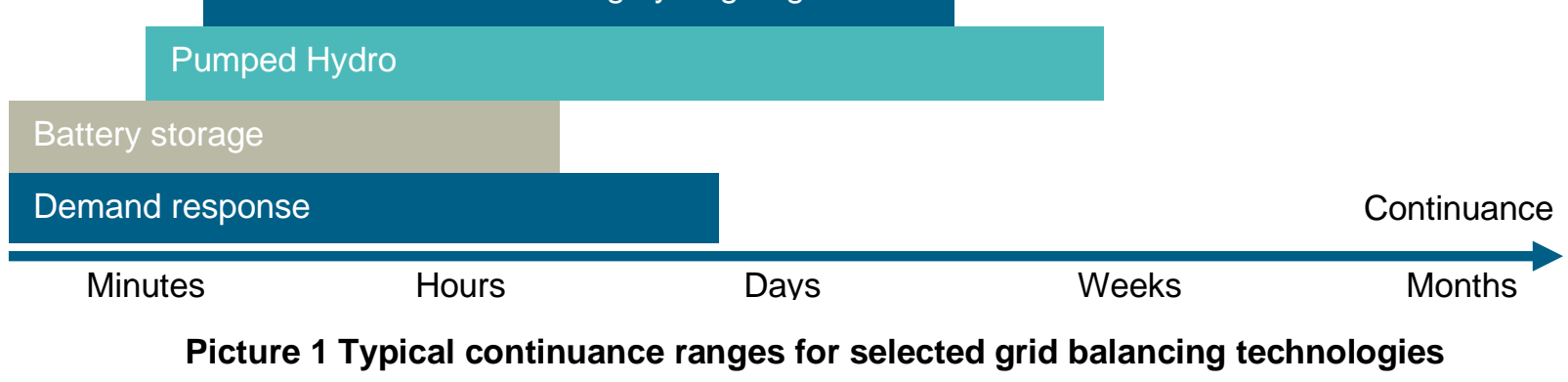

If we now consider a combined cycle of flex design, such plant will be able to both capture the shorter events and be able for continuous operation to cover the rare events when long continuance is required. However, to be cost efficient in the shorter events, a fuel that is cheap but maybe not easily stored in large quantities (or for long periods) may be used, e.g. hydrogen. For the events of longer duration, a second liquid, cheaply stored fuel should complement. If the price difference between these two fuels is small, then the obvious solution is to use only the liquid fuel and avoid the cost of a second fuel system.

If the liquid fuel is expensive it will not matter so much for the rare long continuance events as long as the storage can be made cheap and the fuel is stable for long term storage. There I see methanol and ethanol as strong candidates, but renewable diesel will also be a strong card given the higher energy density even if production cost is higher.

When looking at the price competition between GT combined cycles and storage solutions we can simplify to the following view: When anyway having to construct the GT-plants suited for continuance beyond what ever possible with storage solutions, such GT plant should also be able to participate in daily cycling to gain more dispatch. In daily cycling the GT plants will compete with storage solutions where, for the GT plants, the capex is already spent and further dispatch only will affect opex, mainly fuel cost. For a storage system on the other hand investment needs to be increased in order to prolong continuance to capture more dispatch.

For battery storage, the cycle cost is not affected much by a marginal increase of energy capacity, potentially a small saving can be gained, a larger number of batteries are cycled but the average cycles becomes a bit less deep. If we use the figures in the assumptions above, a battery storage system designed for one-day cycles would have an average electric price of about 150Euro/MWh but the last addition of capacity is even higher, if the GT plants operates on methanol that costs 80 Euro/MWh and efficiency is $60 \%$, then the opex for added electric dispatch is $80 / 0.6=133$ Euro/MWh. Marginal increase for maintenance is rather marginal in relation. This simplification with rough cost estimated indicates the biomethanol as the winner over storage for the full day cycle, for shorter duration of few hours the storage may be the winner 
instead. The future will tell where an intercept lies, where energy storage becomes more expensive than thermal power plants. However, it's evident that it should be at a day scale or less.

\section{DISTRIBUTED VERSUS CENTRALIZED GENERATION.}

Cost to scale will become even more important for balancing power plants that are used as backup after energy storage and demand response have taken care of day-scale peaking, since the Capex part of such plants will dominate. If the idea of reducing need for balancing power by a very large interconnected grid is applied, then that speaks for large and costefficient balancing power plants too. However, some factors point to a benefit for distributed generation. When renewable power is distributed it seems wise to limit transmission by also having both energy storages and the balancing power distributed and fairly co-located with the renewable generation, especially in case on-site hydrogen production should be applied. The prospect of combining remote power generation, e.g. deep-sea offshore wind power or desert location of solar power, with Power to $\mathrm{X}$ and thereby get around the need for transmission is also tempting.

If energy storage is distributed to avoid choking in transmission, then at occasions when balancing power plants are needed, the energy storages would still be needed to level out demand variations. That could result in that expensive renewable fuel burned in the balancing plant is used to charge storages with added losses and cycle cost. This could be avoided by flexible, distributed generation.

CHP plants are already distributed where the heat demand is, which often coincides with electric demand. If they are made flexible by addition of thermal storage, the size of the CHP will be increased to supply the needed heat in a smaller number of hours, resulting in both improved economy by scale and more distributed power generation capacity.

\section{ASSURE FUTURE SAFETY}

The only way to prepare for the future is by assuring operational and fuel flexibility, being future proof. This means that when building a new power plant, one should choose gas turbines of a type that has already good fuel flexibility and that has good probability of adding more fuels when these become available. The plant site should also have ground available for future fuel systems, storage and delivery. Do everything to preserve this reserved plot of ground not to lose the possibility to change fuel supply when time comes.

Environmental and safety aspects of potential new fuels should also be studied, and necessary precautions be taken to keep the options open. Combined risks should also be considered in the case there are neighboring facilities. Pre-permitting may be a good idea to prevent that the neighbor constructs a safety classified plant that may hinder permitting of your future fuel usage.

The bottoming cycle of a new power plant should be designed taking cyclic operation into consideration even if the projected operation initially is base load only. This implies that simple steam systems and less advanced steam conditions should be used even if that compromises performance slightly. Even if no extremely fast starts will be required from all plants, the start-up cost should be kept low by fast steam cycle start. The average efficiency across the operating profile including start and stop cycles is key, not the base load efficiency.

For a CHP plant for district heating I would plan for a large heat storage capable of bridging a few days. If full storage capacity is not constructed from start, I would try to finance at least a 4-hour storage already at start and reserve ground for later additional storage. I would also consider capacity of the plant at the upper end to enable on/off operation to some extent. Further to this, look at the possibility to incorporate a heat pump, if there is no low-grade heat source like a lake available ambient air can be used. A possible application is to store low temperature cooling water used by a power plant (lube oil cooling etc) and lift that heat by a heat pump to district heat temperature when the power plant is stopped due to low electric price.

Owners of an up and running power plant should also make his best to reserve ground space for new fuel usage and keep options open for GT upgrade or replacement to another better suited type, providing the required future readiness. 


\section{REFERENCES}

\section{Books}

Andrei G. Ter-Gazarian 2020, ISBN 978-1-78561-868-0 (PDF) “Energy Storage for Power Systems” $3^{\text {rd }}$ ed. Institution of Engineering and Technology

George A. Olah, Alain Goeppert, and G. K. Surya Prakash, ISBN: 978-3-527-32422-4 "Beyond Oil and Gas: The Methanol Economy" $2^{\text {nd }}$ ed. 2009 WILEY-VCH Verlag GmbH \& Co. KGaA, Weinheim

Lawrence E. Jones 2017 ISBN: 978-0-12-809592-8 “Renewable Energy Integration Practical Management of Variability, Uncertainty, and Flexibility in Power Grids "2 ${ }^{\text {nd }}$ ed. Elsevier Inc. Chapter 17 and 18

\section{Reports}

Battelle Memorial Institute 2016 "Manufacturing Cost Analysis of 100 and $250 \mathrm{~kW}$ Fuel Cell Systems for Primary Power and Combined Heat and Power Applications" Table 10.1

K Mongird et al. 2019, HydroWires Report PNNL-28866 "Energy Storage Technology and Cost Characterization Report" table 4.4 , table 4.13 , pp. 4.44 , table 4.34

S. Huntington and Julian Jansen January 2020, IHS Markit scheduled update "US Battery Storage Capital and Levelized Cost Outlook" pp.14-15

W. Cole and A.W. Frazier, NREL report 2019 NREL/TP-6A20-73222 "Cost Projections for Utility-Scale Battery Storage" Executive Summary 